\title{
Immigration and Congenital abnormalities: Prevalence of Congenital Abnormalities among Children Born to Immigrant and non-immigrant Mothers, Ontario, Canada, 1994-2014
}

\section{Agha, M.M, Galzier, R, Moeineddin, R}

\section{Background}

While considerable advancements have been made in recognition and treatment for congenital abnormalities (CA), there has been little change in the prevalence them even in developed countries, which indicates that there has been no changes in the risk factors that affect Congenital Abnormalities.

Although environmental exposures such as tobacco, air pollution ,pesticides and herbicides have been considered as risk factors, differences in the prevalence of Congenital Abnormalities may be due to variations in genetic predisposition too.

Studies among immigrant population moving from one environment to other, has been considered as one of the ways to explore the role of both genetic background and changes in the environmental factors, especially exposure to food fortification, in occurrence of Congenital Abnormalities. The aim of this study is to compare immigrant and non-immigrant mothers for the prevalence of Congenital Abnormalities and role of possible exposure, like food fortification among immigrant mothers.

\section{Methods:}

This cohort study was based on the follow-up of all children born in hospital in Canada during 1994-2014. Children who had at least one diagnosis from the Congenital Anomalies chapter of the (ICD) in their hospital records during their first year of life were considered to have Congenital Abnormalities. Mother's information including maternal age, and immigration status were linked to child's data through unique health identifiers. For immigrant mothers, immigration status and their date of landing, country of birth and age at the time of landing were included.

\section{Results}

More than 2.5 million live births were identified from hospital records, with $77 \%$ of them born to Non-immigrant mothers and $(23 \%$ of them to immigrant mothers. Prevalence of Congenital Abnormalities among immigrant mothers and nonimmigrant mothers was 60 and 64 per 1000 live births respectively.

:Birth Prevalence of abnormalities based on Landing year of immigrant Mothers in Canada

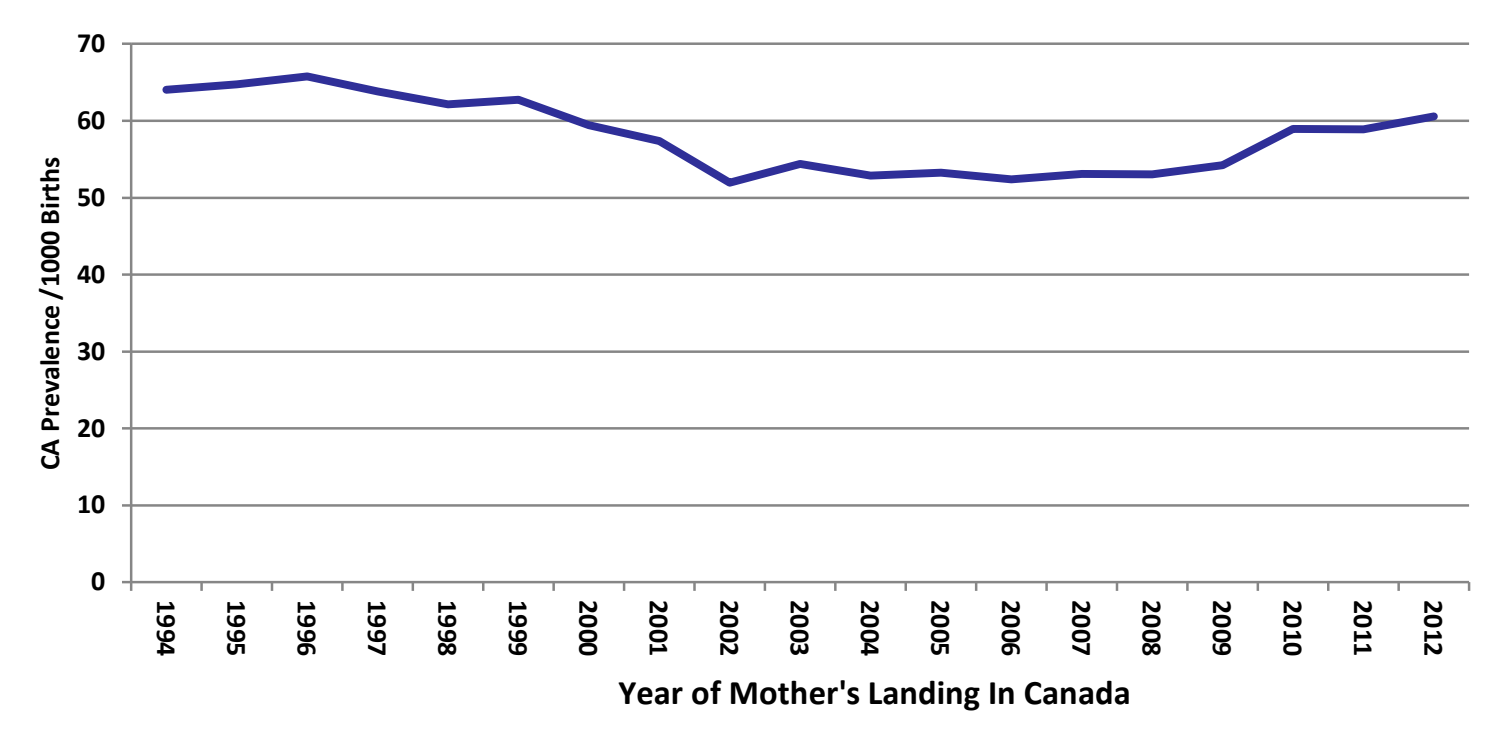

Mothers coming from specific areas such as Caribbean and SubSaharan Africa had higher CA prevalence as compared to Canadian mothers (table 1

). Mothers who migrated to Canada had a lower rates of abnormalities as compared to non-immigrant mothers and duration of stay in Canada did not change it significantly. Although statistically non significant, but the odds of having abnormalities in 2nd and 3rd+ child among immigrant mothers was considerably lower than non-immigrant mothers. While we observed lower rate of abnormalities among mothers coming from certain countries adjusting for possible confounding variable removed the statistical significance for that effect. Although the odds of having a child with abnormalities still higher for mothers coming from Caribbean or Africa, specially for 3rd+ child, but the effect is not statistically significant.

Graph shows the birth prevalence rate of abnormalities amongst immigrant mothers based on year of landing in Canada. Mothers landed before 2000 had higher rates of abnormalities in their children as compared to those landed after 2000. Giving birth after food fortification was significantly associated with lower risk of having abnormalities. This was true for all birth orders.

This study is the first study to explore the time trend of occurrence of congenital anomalies among immigrant population. While this study gave us the opportunity to explore the role of many important risk factors such length of stay, risk level in mother's country of birth, birth order and also impact of food fortification, but unfortunately we do not have access to data on abortions in this population.

Table 1 : Birth Prevalence (/1000) of congenital abnormalities based on mother's area of origin

\begin{tabular}{|l|l|l|l|l|l|}
\hline World Area & Numerator & Denominator & Rate/1000 & \multicolumn{2}{|c|}{ RR (95\% CI) } \\
\hline Canada & $\mathbf{2 0 0 1 2 5 1}$ & $\mathbf{1 2 6 5 0 5}$ & $\mathbf{6 3 . 2}$ & \multicolumn{2}{|c|}{ Reference group } \\
\hline & & & & & \\
\hline Caribbean & 38905 & 2788 & 71.7 & 1.13 & $(1.09-1.18)$ \\
\hline Sub-Saharan Africa & 49620 & 3312 & 66.7 & 1.06 & $(1.02-1.09)$ \\
\hline East Asia and Pacific & 137579 & 8195 & 59.6 & 0.94 & $(0.92-0.96)$ \\
\hline Middle East and North Africa & 54637 & 3211 & 58.8 & 0.93 & $(0.90-0.96)$ \\
\hline South Asia & 172901 & 10160 & 58.8 & 0.93 & $(0.91-0.95)$ \\
\hline Hispanic America & 46760 & 2581 & 55.2 & 0.87 & $(0.84-0.91)$ \\
\hline Western Nations and Europe & 96008 & 5170 & 53.8 & 0.85 & $(0.83-0.88)$ \\
\hline
\end{tabular}

Table 3 : Prevalence of congenital abnormalities based on mother's area of origin and Birth Order

\begin{tabular}{|c|c|c|c|c|}
\hline \multirow[t]{2}{*}{ World Area } & \multicolumn{3}{|c|}{ Rate of abnormalities / 1000 in Births } & \multirow[t]{2}{*}{$\operatorname{RR}\left(3^{\text {rd }}+/ 1^{\text {st }}\right)$} \\
\hline & $1^{\text {st }}$ Birth & $2^{\text {nd }}$ Birth & $3^{\text {rd }}+$ Birth & \\
\hline Canada & 65.5 & 59.2 & 60.9 & 0.93 \\
\hline Caribbean & 74.6 & 68.5 & 63.0 & 0.84 \\
\hline Sub-Saharan Africa & 61.7 & 55.0 & 56.8 & 0.92 \\
\hline East Asia and Pacific & 56.5 & 53.7 & 48.0 & 0.85 \\
\hline Middle East and North Africa & 60.5 & 55.9 & 55.0 & 0.91 \\
\hline South Asia & 62.9 & 53.8 & 50.8 & 0.81 \\
\hline Hispanic America & 70.3 & 62.7 & 62.7 & 0.89 \\
\hline Western Nations and Europe & 55.3 & 51.4 & 52.4 & 0.95 \\
\hline
\end{tabular}

